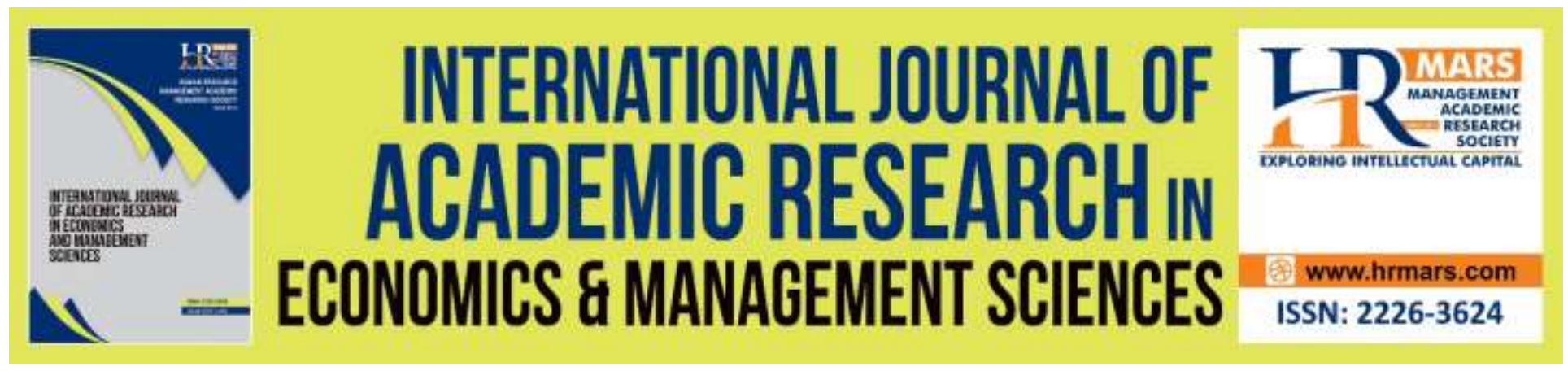

\title{
Intellectual Property Rights (IPRS) And Unemployment: Empirical Evidence from Developing Economies
}

Asuantri Mohamad, Yasmin Bani, Shivee Ranjanee Kaliappan, Suryati Ishak

To Link this Article: http://dx.doi.org/10.6007/IJAREMS/v9-i2/7343

DOI: 10.6007/IJAREMS/v9-i2/7343

Received: 15 April 2020, Revised: 19 May 2020, Accepted: 29 May 2020

Published Online: 18 June 2019

In-Text Citation: (Mohamad et al., 2020)

To Cite this Article: Mohamad, A., Bani, Y., Kaliappan, S. R., \& Ishak, S. (2020). Intellectual Property Rights (IPRS) And Unemployment: Empirical Evidence from Developing Economies. International Journal of Academic Research in Economics and Managment and Sciences, 9(2), 1-16.

Copyright: (C) 2020 The Author(s)

Published by Human Resource Management Academic Research Society (www.hrmars.com)

This article is published under the Creative Commons Attribution (CC BY 4.0) license. Anyone may reproduce, distribute, translate and create derivative works of this article (for both commercial and non-commercial purposes), subject to full attribution to the original publication and authors. The full terms of this license may be seen at: http://creativecommons.org/licences/by/4.0/legalcode

Vol. 9, No. 2, 2020, Pg. 1 - 16

http://hrmars.com/index.php/pages/detail/IJAREMS

JOURNAL HOMEPAGE

Full Terms \& Conditions of access and use can be found at http://hrmars.com/index.php/pages/detail/publication-ethics 


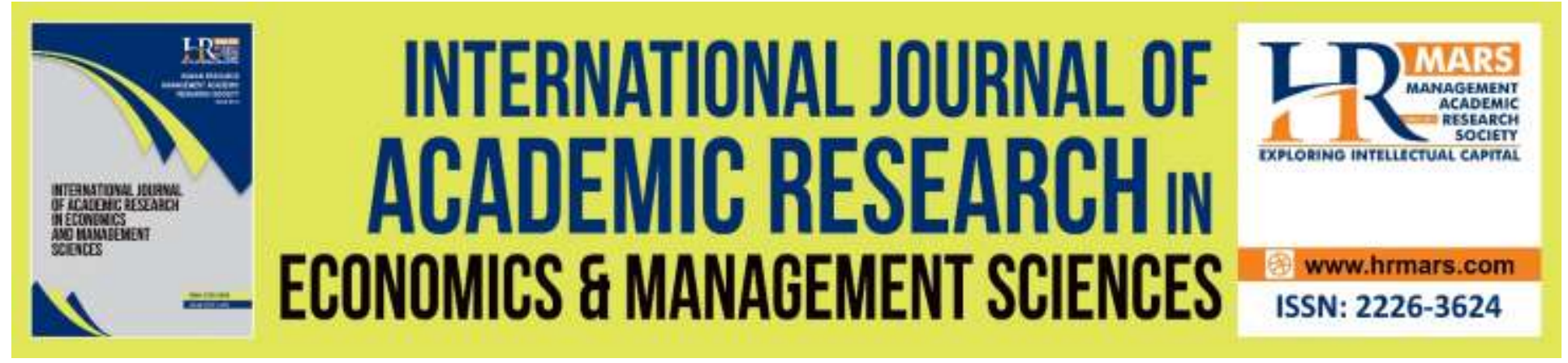

\title{
Intellectual Property Rights (IPRS) And Unemployment: Empirical Evidence from Developing Economies
}

\author{
Asuantri Mohamad, Yasmin Bani, Shivee Ranjanee Kaliappan, \\ Suryati Ishak \\ School of Business and Economics, Universiti Putra Malaysia, 43400 Serdang, Selangor, \\ Malaysia \\ Email: asuantri@gmail.com,nor_yasmin@upm.edu.my, shivee@upm.edu.my, \\ suryatiis@upm.edu.my
}

\begin{abstract}
Developing countries rely on imitation and innovation to boost their economic growth. The debate on innovation and imitation has been the focus of empirical research with the implementation of strengthening Intellectual Property Rights (IPRs). This is because IPRs may affect developing countries in terms of employment and economic growth. Theoretical studies have proven the relationship, but empirical studies on this topic are scarce. Thus, this study aims to examine the effect IPRs on unemployment in selected developing economies. System-GMM estimator is adopted by utilizing panel data for a sample of 47 developing countries from 20082014. This study considers the direct effect of IPRs protection on unemployment. The empirical analysis shows that stronger IPRs protection escalates unemployment in these countries as evidenced by a positive and significant relationship between these variables. As most of the technology by developing countries rely on imitation activities thus, stronger IPRs protection increases unemployment and the effect of IPRs protection on unemployment are positive.

Keywords: IPRs Protection, Unemployment, System-GMM, Developing Countries.
\end{abstract}

\section{Introduction}

The enforcement of IPRs protection all over the world is found to have an effect on unemployment in developing countries. Essentially, the differences in the level of IPRs protection between developed and developing countries lead to increased unemployment, especially in developing countries. This is because strengthened IPRs protection may affect imitation activities in developing countries since most of the innovation in these countries is imitated from developed countries. Meanwhile, the reduction of imitation activities will slow down economic 
activities. The IPRs protection requires a cost for its maintenance; thus, the country will competitively be at a disadvantage, which might increase unemployment.

International Labour Office (ILO) definition of unemployment covers all individuals that are economically identified as an active population but without work, or not employed either through employment or self-employment. Additionally, it is also considered as being "currently available for work", which denotes the availability for paid employment or self-employment during the reference period as well as "seeking work" where the individuals seek employment or self-employed. There are several types of unemployment such as frictional, structural and cyclical unemployment. Frictional unemployment occurs as a result of the movement of labor from or out of their jobs. Levine (2013) defined frictional unemployment as two ways' movement of workers, either from unemployed into employed or vice versa. The duration of frictional unemployment is possibly shorter than structural unemployment since frictional unemployment is more of a temporary condition.

On the other hand, structural unemployment refers to unemployment that occurs due to the incompatibility of unemployed workers' skills with the jobs that are available in the market. Likewise, a long recession period may also commonly create structural unemployment for unemployed workers. This is because a long period of being unemployed would diminish the workers' skills and the skills become outdated. As technology grows rapidly, the workers' skills might be incompatible with the current technology; as a result, the workers will possibly continue to be unemployed. Accordingly, cyclical unemployment also arises when an economy is facing lower demand for goods and services and the workers are being laid off. Additionally, in certain cases, the employer also cuts off the working hours of the workers. However, this unemployment gradually decreases after the demand for the product is revived.

In most economies, a high level of employment is an indication of the high efficiency of the labor market, whereas unemployment potentially indicates the inefficient use of labor in the market. Simultaneously, it also reveals the weaknesses of the economy in providing jobs in the market. Thus, inefficient labor usage and the presence of a mismatch between labor supply and demand in the market possibly increase unemployment in the country. Consequently, researchers such as Arnold (2002) argued that strengthened IPRs protection leads to an increase in unemployment in developed countries. Accordingly, strengthened IPRs protection encourages the North (developed countries) production to be transferred to the South (developing countries) due to the availability of low labor cost and high imitative ability in the South, thereby leading to an increase in frictional unemployment in the North. Similarly, an increase in frictional unemployment is driven by the imitation of technologies by developing countries due to the high imitation rate in these countries. Consequently, the presence of frictional unemployment in the developed countries forces the workers into unemployed situations.

On the other hand, the effect of strengthened IPRs protection in developing countries may be cushioned by reducing the production of counterfeit products, for example, software, books and other products with weak IPRs protection. Meanwhile, a decrease in production may cause a displacement of the resource, especially in the counterfeiting industries that are affected by strengthened IPRs protection, thereby causing an increase in unemployment. The effect of IPRs protection on unemployment depends on the capability of the firms in the industries to respond to strengthened IPRs protection. For example, moving to the other industry and supported by current skilled workers as well as the market demand for the new product produced by new 
industries. However, strengthened IPRs protection may cause an upgrading of the output into a higher quality product in order to keep sustaining the market. Thus, the output of counterfeiting industries should be replaced or enhanced. In this situation, there is the possibility of counterfeiting industries to sustain and maintain employment, thus, reducing unemployment if they successfully move parallel with stronger IPRs protection. On that premise, this study is more interested in investigating the impact of IPRs protection on unemployment in developing countries.

Thus, this paper aims to study the relationship between IPRs protection and unemployment which are mainly neglected empirically. Even though the relationship has been explored and explained theoretically, there are no empirical studies to validate the model proposed in the existing literature. The dearth of empirical evidence motivated this study and the findings will fill in the gaps of the IPRs-unemployment nexus literature.

\section{Literature Review}

According to the North-South theory by Mondal and Gupta (2008), products are typically invented in the North and are typically imitated by the South, where the linkage between North and South is free to trade of differentiated products. The North will bear the innovation costs for their invention of new products and gain monopoly profits from these products up to the point where these products are imitated by potential firms in the South. According to theory, the North is fully protected in terms of patent and IPRs protection. However, in the South, the patents are not perfectly protected; thereby, leading to imitation activities. In the South, the labor cost is relatively low; hence, lowering the imitation cost. There are two types of labor in the labor market of the South, which are skilled workers and unskilled workers. The theory assumes that the efficiency of unskilled workers positively varies with the relative wage of unskilled workers to skilled workers. Thus, the level of the endowment of the South's unskilled workers expressed as an efficiency unit is endogenous in this model.

Mondal and Gupta (2008) further explain the effect of stronger IPRs protection on growth (innovation) and imitation rates, the narrow technology gap case is similar to those in the wide technology gap case. In other words, an increase in IPRs protection reduces the skilled workers for the production sector in the South when the growth rate is given. Consequently, this decreases the rate of imitation because the relative sales volume of a Northern firm to a Southern firm is constantly in the narrow gap case. With the reduced imitation rate, both the profit rate and cost of capital of a typical firm in the North are reduced as well. The former effect dominates the latter; hence, the rate of innovation is reduced. Stronger IPRs protection in the North causes more firms to remain there, which increases the demand for production labor and the relative wage in the North. Meanwhile, the increase in skilled workers in the imitative R\&D sector in the South reduces the rate of product development (growth). However, this negative impact is very weak. Consequently, the overall skilled labor employment in the imitative R\&D sector by which its size is measured increases with stronger IPRs protection. The introduction of efficiency wage function leads to unemployment equilibrium for the market of unskilled workers in the South. Moreover, the level of the endowment for Southern skilled workers is exogenously given and fully employed. Skilled workers are employed in imitation activities and production, whereas unskilled workers are employed only in the production sector. In this context, the North acquires 
only skilled workers for both productions as well as R\&D activities, where the level of the endowment is given and fully employed.

The theory proposed by Arnold (2002) asserts on the South-North trade with the integration of North (developed countries) and South (developing countries) with intra-industries. Initially, the products are innovated in the North, which gives them monopoly power. However, due to the high imitation rate and low labor cost availability in the South, products originated from the North are imitated in the South. Moreover, the transfer of production from North to South increases the unemployment rate in the North, since these products are no longer produced there, which subsequently leads to frictional unemployment in the North. The differences in both technology diffusion and level of IPRs protection between North and South lead to the imitation of products in the latter. Therefore, increased IPRs protection and lower imitation rate are expected to reduce unemployment.

According to the theory of the growth effect of North-South trade proposed by Arnold (2002), high imitative ability and lower level of IPRs protection in the South (developing countries) would shift the production from the North to the South, which would contribute to frictional unemployment in the North. Accordingly, frictional unemployment would occur since the product produced in the North would be produced in the South instead. The implication is that these unemployed workers would have to search for new employment to enter the labor force. Low level of IPRs protection particularly in the developing countries would increase the level of unemployment, especially in these countries.

The theory is also supported by Hasan et al. (2012) who conduct the industry-level and statelevel analysis using weighted least square (WLS) based on the Indian data between 1987 and 2005. The unemployment data is from the survey of 'employment-unemployment' carried out by India's National Sample Survey Organisation (NSSO). In particular, the study reveals that under low trade reform, unemployment in the net exporter industries would likely increase. Furthermore, the state-level analysis shows that increase in employment and a decline in urban unemployment are parallel with trade liberalization and flexible labor markets in net exporter industries. Moreover, lower trade reform tends to increase unemployment, especially in net exporter countries.

The relationship between stronger IPRs protection and unemployment is negative as proven by Shin (2017). The author employs a fixed and random effect model based on the 10-years data between 2006 until 2015 and uses 16 provinces in South Korea. The author finds a negative and statistically significant relationship between IPRs protection and unemployment in South Korea. In other words, higher IPRs protection reduces unemployment. Accordingly, Shin (2017) reiterates that the relationship between IPRs protection and unemployment is statistically significant only in the capital area of South Korea.

Apart from that, the sustainability of firms in the market also has a significant impact on influencing the roles of IPRs protection on unemployment. This is because new and mature firms reveal a different capability to innovate or imitate which would influence the effect of IPRs protection on unemployment within a country. Consequently, Balsmeier and Delanote (2015) confirm these different effects of IPRs protection on unemployment by considering young and matured industries based on fixed and random effect models for 23 transition economies. They find that younger and mature industries experienced different effects according to the level of IPRs protection where young industries benefited from higher IPRs protection, whereas mature 
industries benefited from lower IPRs protection in terms of the employment rate. It further implies that higher IPRs protection would increase the employment rate in young industries.

The type of industries in the economies is also one of the important factors in explaining the relationship between IPRs protection and unemployment in a country. For example, developing countries that attempt to imitate the technology from developed countries are normally involved in heavy industries and require a higher number of low-skilled workers. Thus, improvement in IPRs protection increases substantial unemployment in the short run (Fink, 2008). Additionally, stronger IPRs protection limits the employment for these low-skilled workers in the industries that depend on producing counterfeit and pirated goods. However, there is a different scenario in developed countries in the relationship between IPRs protection and unemployment which is theoretically explained as stronger IPRs protection leads to frictional unemployment. This relationship is frequently discussed in the previous studies by way of different levels of IPRs protection and labor cost matters between developed and developing countries (Arnold, 2002).

\section{Model and Methodology}

To examine the effect of IPRs protection on unemployment in developing countries, this study chooses the unemployment rate as a percentage of the total labor force in developing countries as a proxy for unemployment. The main variable of interest is IPRs protection (IPR) and the control variables were chosen are education (EDU), wages (WAGES), population (POP), economic growth(GDP), and inflation (CPI). A panel dataset was extracted from 47 selected developing countries for a period of seven years (2008-2014) and the countries chosen are listed in the appendix. The limited number of countries and the short sample period is due to the availability of the variables of interest. The proposed empirical model is adopted from Shin (2017) and the proposed empirical model for this study is as follows:

$\operatorname{LUNEMP}_{i t}=\beta_{0}+\beta_{1} L U N E M P_{i t-1}+\beta_{2} L I P R_{i t}+\beta_{3} L W A G E S_{i t}+\beta_{4} L P O P_{i t}+\beta_{5} L G D P_{i t}+$ $\beta_{6} L E D U_{i t}+\beta_{7} L C P I_{i t}+\mu_{i t}$

where $\mathrm{i}(1,2,3, \ldots, \mathrm{i})$ denotes country index; $\mathrm{t}(1,2,3, \ldots, \mathrm{t})$ denotes time index; and the coefficient of $\beta_{2}$ explains how IPRs protection affects unemployment. All the variables are converted into a log form. Since we are interested in studying the dynamic nature of the variables, the lagged dependent variable is included in the regression.

The main variable of interest which is IPR protection is an index developed by the Property Right Alliance (2017) and segregated from the International Property Rights Index (IPRI). IPRI contains several individual indexes and one of them is IPRs protection. The individual index of IPRs protection is used to avoid any multicollinearity issue that may arise as the IPRI index contains several indexes that may correlate with other independent variables used in the estimation. The expected sign for IPRs is positive.

In order to capture the effect of wages on unemployment, the nominal gross monthly wage is extracted from the International Labour Organization (ILO) data. The remaining control variables are taken from the World Development Indicator (WDI), World Bank which are education, GDP per capita, and CPI index. This study adopted the enrolment in tertiary education as a proxy for the level of education in the selected developing countries. The enrolment of tertiary education is more appropriate as this proxy measures higher education participation. Besides, LGDP is the 
log of GDP per capita (constant 2010 US\$) to proxy for the level of economic development in developing countries. LPOP is the log of the population aged 15-64 years old and this proxy is used to capture an active working population in the selected developing countries. LCPI is the log of the consumer price index and frequently used to proxy for inflation because the CPI index measures the average prices of consumer goods and services. Wages are typically considered as one of the most important variables in the literature when examining the relationship with unemployment. Theoretically, wages are expected to have a negative relationship with unemployment. This is because an increase in wages induces labor to enter the labor force and encourages labor to increase their effort and productivity in the workplace. This proxy was also used by Bellak, Leibrecht, and Riedl (2008) in their study.

The working population accounts for the demographic transition in the economy that is related to the size of the labor force. An increase in the population is expected to increase unemployment in a country if there are not enough jobs available. This variable is employed by Abegunde et al. (2007) and a positive relationship is expected between population and unemployment. Economic growth is theoretically found to have a significant impact on unemployment. In this regard, GDP per capita is used as a proxy for economic development, given that sustained economic growth would reduce unemployment as discussed in previous studies, such as Haydaroglu (2015). Thus, the relationship between economic growth and unemployment is expected to be negative.

Several proxies have been used to measure education level, such as average years of secondary schooling in the population and enrolment in secondary education (see; Falvey et al., 2009). However, this study considers enrolment in tertiary education as a proxy for education level as Hannum and Buchmann (2005). A negative sign is expected since an increase in education level means the population is more educated and the probability of getting employed is higher which will reduce unemployment in the country. The consumer price index (CPI) is to measure inflation, cost of living, and also as an indicator for macroeconomic stability as adopted by (Falvey \&Foster, 2006; Shin, 2017). In this regard, inflation is one of the macroeconomic indicators that reveal economic and social problems (Wajid, 2013). The relationship between these two variables is expected to be positive, where an increase in inflation tends to increase unemployment in a country. However, there is a contrary assumption regarding this matter, given holding the facts that, when inflation is expected to increase, this would stimulate the workers to enter the labor force. The negative relationship between inflation and unemployment described as 'labor tensions' and intensively explained by Vignolles Benjamin (2018).

This study adopts different regression methods which are pooled OLS, Fixed and Random effect, difference GMM and system GMM. Since education and economic growth are used as explanatory variables in this estimation, endogeneity is expected. This is because reverse causality may run between education and economic growth or between economic growth and education. It can be the fact that higher economic growth leads to higher spending on education. On the other hand, a country with higher education promotes better economic growth. Adopting panel data would solve the problem; however, the Fixed Effect model only eliminates timeinvariant heterogeneity across countries, but not the time-varying country effects. In this regard, the time-varying country effects still exist in the estimation and may create an endogeneity problem. Due to its relative advantage in improving precision and reducing finite-sample bias, we adopt the two-step system GMM estimator as our preferred estimator. In order to illustrate the system GMM, the general form of the empirical model is outlined as follows: 
$U_{i t}-U_{i t-1}=(\alpha-1) U_{i t-1}+X^{\prime}{ }_{i t} \beta+\eta_{i}+\gamma_{t}+\varepsilon_{i t}$

where $U$ is the logarithm of unemployment; $X$ is the set of explanatory variables other than the lagged unemployment; $\eta$ is an unobserved country-specific effect; $\gamma$ is a time-specific effect; $\varepsilon$ is the independent and identically distributed error term; $i$ represents the country, and $t$ represents the time period. Equation 2 can be rewritten as:

$U_{i t}=\alpha U_{i t-1}+X^{\prime}{ }_{i t} \beta+\eta_{i}+\gamma_{t}+\varepsilon_{i t}$

In order to eliminate the country-specific effect, the first difference of equation 3 is expressed as below:

$\Delta U_{i t}=\alpha \Delta U_{i t-1}+\Delta X^{\prime}{ }_{i t} \beta+\Delta \gamma_{i}+\Delta \varepsilon i t$

The system GMM overcomes the bias problems of the difference GMM estimator by taking both equations 3 and 4 together. The estimator assumes that the country-specific effect is uncorrelated with the first difference of the dependent and the independent variables. Consequently, along with the usual assumptions of the difference GMM, system GMM has two extra moment conditions, which are the correlation between the dependent variable and the error term, and the independent variables and the error term. According to Blundell and Bond (1998), in the condition of a small number of the time period and the persistence of time series, the first-differenced GMM estimators are likely to perform poorly. This can be explained as the lagged levels serve only weak instruments for the differenced equations. Besides, by using the difference estimator the process of differencing to remove the country-specific effect usually eliminates information on the cross-country variation in levels. However, the system GMM estimator combines the standard set of moment conditions in the first differences with lagged levels as instruments, with an additional set of moment conditions derived from the equation in levels (see: Arellano and Bover, 1995 and Blundell and Bond, 1998). The assumption of the availability of additional moment conditions also depends on the correlation between $X_{i t}$ and the country-specific effect $\eta_{i}$. According to Blundell and Bond (1998), it depends on the assumption that the difference of $X_{i t}$ is uncorrelated with the individual effects while $X_{i t}$ and $\eta_{i}$ are allowed to be correlated. The moment conditions are illustrated below:

$\left[\Delta U_{\mathrm{i}, \mathrm{t}}-\mathrm{s}, \Delta \varepsilon_{\mathrm{i}, \mathrm{t}}\right]=0, \geq 2, t=3, \ldots T$

$\left[\Delta X_{i \mathrm{t}},-s, \Delta \varepsilon_{i, t}\right]=0, \geq 2, t=3, \ldots T$

The efficiency and consistency of the GMM estimator depend on the absence of serial correlation and the validity of lagged values as instruments. The autocorrelation test needs to be implemented in the estimation in addition to the Arellano-Bond test of autocorrelation. The test has a null hypothesis of no autocorrelation and tests whether the differenced error term is correlated. The test rejects the null hypothesis for $A R(1)$ but should not reject the null for $A R(2)$. To test the validity of the instruments, we use the Hansen J test of over-identifying restrictions. The null hypothesis of this test states that the instruments are exogenous. This test has a Chi- 
INTERNATIONAL JOURNAL OF ACADEMIC RESEARCH ECONOMICS AND MANAGEMENT SCIENCES

Vol. 9, No. 2, 2020, E-ISSN: 2226-3624 ㄷ 2020 HRMARS

square distribution with $\mathrm{j}-\mathrm{k}$ degrees of freedom; $\mathrm{j}$ being the number of instruments and $\mathrm{k}$ is the number of regressors.

\section{Empirical Result}

Table 1 illustrates the descriptive statistics of the variables used in the model. The mean value of the main variable, IPRs protection, is 1.4044 , with a standard deviation of 0.2753 . The maximum and minimum values are 2.0541 and 0.5110 , respectively. The average population size of the developing countries is 4.1213 , with a standard deviation of 0.1254 . The maximum and minimum values for the population size are 4.3086 and 3.8735 , respectively. The mean value of education is 2.86583, with a corresponding standard deviation of 1.0499. The maximum and minimum scores for education are 4.4239 and -0.5447 , respectively. The average value of GDP per capita is 7.6981, and its maximum value is 9.3853 , with a standard deviation of 1.0733 . The summary of statistics indicates that the average value of CPI is 4.6650, with a standard deviation of 0.1425 , while the maximum and minimum values are 5.3262 and 4.3194 , respectively. The mean value of wages as shown in the table is 5.4661, with a standard deviation of 1.4547 . The maximum and minimum scores for wages are 10.3617 and 1.7918 , respectively.

Table 1: Descriptive Statistics

\begin{tabular}{lccccc}
\hline Variables & Obs. & Mean & Std. Dev & Min & Max \\
\hline Log Unemployment & 329 & 1.8112 & 0.7994 & -0.7133 & 3.2308 \\
Log IPRS protection & 283 & 1.4044 & 0.2753 & 0.5110 & 2.0541 \\
Log Population & 329 & 4.1213 & 0.1254 & 3.8735 & 4.3086 \\
Log Education & 317 & 2.8583 & 1.0499 & -0.5447 & 4.4239 \\
Log GDP & 329 & 7.6981 & 1.0733 & 5.4373 & 9.3853 \\
Log CPI & 329 & 4.6650 & 0.1425 & 4.3194 & 5.3262 \\
Log Wages & 284 & 5.4661 & 1.4547 & 1.7918 & 10.3617 \\
\hline
\end{tabular}

Table 2 indicates the results of Pooled OLS in column 1, followed by the Fixed Effect in column 2 and Random Effect in column 3. Based on the results, IPRs protection and GDP per capita are positive and significantly related to unemployment. In other words, this result suggests that stronger IPRs protection and economic growth increase unemployment. Inflation and population are negative and significant, which is in contrast with the theoretical expectations. The results reported in Table 1 indicate that there are inconsistencies in the significance and coefficients sign between the independent variables. The results illustrate the possible problem of endogeneity that may arise from reverse causality between the variables. It can also be an indication that the relationship between the variables is dynamic, hence applying the static panel method is not suitable. The estimated coefficients may be biased if we do not take into account the above 
problem. Hence, we resort to a more suitable and powerful method that is able to overcome the problems, which is system GMM proposed by Arellano and Bond (1991). System GMM takes the first-differences of the model to eliminate fixed effects and then applies GMM to the first difference model. It uses the level of lagged variables as the instruments (Arellano \& Bond, 1991), making it more efficient and consistent.

Even though the dynamic panels are efficient, it was affirmed that system GMM is more efficient compared to difference GMM as difference GMM may have a poor finite sample property and suffer from weak instruments bias; if the lagged levels of the series are only weakly correlated with subsequent first differences, the instruments are weak. These problems would be detected in the condition of highly persistent Consequently, it may lead to biased estimates especially in a small sample. Even though the proliferation of the instruments in the system GMM may overfit the endogenous variables leading to loss of power, in this case, the maximum lag length of the lagged instruments can be controlled.

Table 2: Results of Pooled OLS, Random Effects and Fixed Effects estimations Pooled OLS

Variables

LIPR

$\angle P O P$

LEDU

LGDP

$L C P I$

LWAGES

Constant

(OLS)

0.060

$-2.323 * * *$

0.120

(0.099)

$0.443 * * *$

(0.092)

$-0.985^{* *}$

(0.465)

$-0.027$

(0.035)
(2)

Fixed Effect

(FE)

$0.397^{* * *}$

(0.129)

$-5.175^{*}$

(2.803)

0.144

(0.158)

$-0.566$

(0.440)

$-0.584 * *$

(0.237)

0.142 *

(0.075)

28.499**

(11.506)
(3)

Random Effect (RE)

$0.318^{* * *}$

$0.355^{* *}$

$-0.797 * * *$

(0.203)

0.069

(0.053)

$9.863^{*}$

\begin{tabular}{lccc} 
& $(3.808)$ & $(11.506)$ & $(5.269)$ \\
\hline No of observations & 236 & 239 & 236 \\
R-Squared & 0.207 & 0.111 & 0.168 \\
\hline
\end{tabular}

Note: Standard errors in parentheses, ${ }^{* * *} p<0.01, * * p<0.05, * p<0.1$. The dependent variable in each regression is the log of unemployment and the number of countries that included in the regression is 47 developing countries. Significant time dummies are included in every regression.

Table 3 shows that the results of difference GMM are reported in column 1, whereas, the results of system GMM are presented in column 2. The main variable of interest (IPRs protection) turned 
out with a negative sign and insignificant in difference GMM. A comparison of results between difference GMM and system GMM shows that system GMM is a more efficient estimator as difference GMM may suffer from weak instrument bias as previously discussed. This is evidenced in the presence of an inappropriate sign of the coefficient in the estimation and the variables may turn out to be insignificant as presented in column 1.

Table 3: Results of difference GMM and system GMM estimations

\begin{tabular}{lcc}
\hline \multicolumn{1}{c}{ Variables } & $(1)$ & $(2)$ \\
& Difference GMM & System GMM \\
\hline LUNEMP $P_{t-1}$ & $0.324^{* * *}$ & $0.941^{* * *}$ \\
LIPR & $(0.051)$ & $(0.027)$ \\
& -0.068 & $0.280^{* * *}$ \\
LPOP & $(0.051)$ & $(0.066)$ \\
& $4.655^{* * *}$ & 0.091 \\
LEDU & $(1.697)$ & $(0.173)$ \\
& 0.059 & $0.069 *$ \\
LGDP & $(0.128)$ & $(0.039)$ \\
& 0.484 & $-0.109 * * *$ \\
LCPI & $(0.303)$ & $(0.033)$ \\
& $-0.898 * * *$ & $-0.146 *$ \\
LWAGES & $(0.116)$ & $(0.074)$ \\
Constant & -0.033 & -0.005 \\
& $(0.083)$ & $(0.011)$ \\
Observations & - & 0.689 \\
AR 1 [ $p$-value] & & $(0.700)$ \\
AR 2 [ $p$-value] & 169 & 216 \\
Hansen J [p-value] & 0.073 & 0.071 \\
\hline
\end{tabular}

Note: Standard errors in parentheses, ${ }^{* * *} p<0.01,{ }^{* *} p<0.05, * p<0.1$. The dependent variable in each regression is the log of unemployment and the number of countries that included in the regression is 47 developing countries. Significant time dummies are included in every regression.

Using system GMM, IPRs protection is positively related to unemployment at $1 \%$. This implies that stronger IPRs protection is expected to increase unemployment in the sample countries. Theoretically, strengthened IPRs protection will increase unemployment in developing countries. Since most of the developing countries imitate the technology from developed countries, strengthened IPRs protection will limit the imitation activities and increase the cost of imitation. Additionally, it can be argued that the positive coefficient is due to the difference in the level of the technology between the sample countries in previous studies. The lagged dependent variable 
is also positive and significant which implies that the dynamic panel method is suitable to analyze the relationship of the variables.

Accordingly, as technology may create a positive contribution to economic growth, IPRs protection secures the innovated technology, thus, promoting a sustainable economic growth that may reduce unemployment. A negative and highly significant relationship is found between GDP per capita and unemployment in this study. The findings of this study are in line with the previous study by Awad and Youssof (2016) which demonstrate a negative relationship between GDP per capita and unemployment. Education has a positive relationship with unemployment, and this is significant at $10 \%$. This finding is consistent with a previous study by Shin (2017) who reveals that higher expenditure on education in the developing countries might be tracked by increases in unemployment. A possible explanation for the positive relationship between education and unemployment is that the higher the educational attainment, the higher the unemployment rate would be. This is because the employees with higher education might spend an appreciable amount of time searching for the appropriate job. Hence they might be unemployed during this waiting period, unlike people with lower educational attainment who may accept any kind of job within the shortest period

Inflation is negatively related to unemployment and significant at $10 \%$. This outcome is parallel with several studies (for example Furuoka, 2007; Awad \& Youssof, 2016), which report an inverse relationship between $\mathrm{CPI}$ and unemployment. Theoretically, in the short-run, along with the acceleration of inflation, employees tend to supply more labor with the expectation of rising inflation. With the expectation of rising inflation, people seek jobs and enter the labor force, hence, lowering the unemployment rate. The persistent high supply of labor in the labor force is bound to minimize unemployment in the country. Other explanatory variables which are population and wages are insignificant to explain unemployment in developing countries.

In order to validate the consistency and efficiency of the model, we conduct the first-order and second-order autocorrelation test of Arellano-Bond and Hansen Test. The tests reveal that the null hypothesis of the first-order autocorrelation is rejected; conversely, the null hypothesis of the second-order autocorrelation test is not rejected. Furthermore, the $p$-value of the Hansen test is insignificant, which means that we do not reject the null hypothesis of valid instruments. Therefore, the results of the diagnostic tests are satisfactory. The rejection of the first-order autocorrelation (AR1) and the absence of second-order serial correlation (AR2) in this estimation validates the system GMM as an appropriate estimator.

We also run three additional regressions to test the robustness and the sensitivity of the model and the results. Since there are three elements of indexes in the formation of IPRI, we use another two indexes for robustness checks. Column 1 in Table 4 reports the result for the robustness check using legal and political score whereas column 2 reports the result of the second robustness check using the physical index as a proxy of IPRs protection. Besides, we also add other independent variables to test the sensitivity of the estimated model following Wajid (2013) and the results are reported in Column 3. The positive sign of IPRs protection on unemployment is significant and in line with the result in the baseline model. The result implies that a $1 \%$ increase in IPRs protection will increase unemployment by $0.305 \%$. The additional control variables are also similar to the baseline model in terms of magnitude. The lagged dependent variable is still positive and significant which implies the validity and robustness of the method. 
Table 4: Robustness Checks

\begin{tabular}{|c|c|c|c|}
\hline Variables & $\begin{array}{c}\text { (1) } \\
\text { System GMM } \\
\text { Legal Index }\end{array}$ & $\begin{array}{c}\text { (2) } \\
\text { System GMM } \\
\text { Physical Index }\end{array}$ & $\begin{array}{c}\text { (3) } \\
\text { System GMM } \\
\text { Add: Trade }\end{array}$ \\
\hline LUNEMP $_{t-1}$ & $\begin{array}{c}0.846 * * * \\
(0.037)\end{array}$ & $\begin{array}{c}0.894 * * * \\
(0.025)\end{array}$ & $\begin{array}{c}0.955^{* * *} \\
(0.030)\end{array}$ \\
\hline$L I P R$ & $\begin{array}{c}0.305^{* *} \\
(0.144)\end{array}$ & $\begin{array}{c}0.369 * * \\
(0.148)\end{array}$ & $\begin{array}{c}0.135^{* * *} \\
(0.050)\end{array}$ \\
\hline$\angle P O P$ & $\begin{array}{l}-0.519 \\
(0.306)\end{array}$ & $\begin{array}{c}0.301 \\
(0.218)\end{array}$ & $\begin{array}{c}0.066 \\
(0.293)\end{array}$ \\
\hline$\angle E D U$ & $\begin{array}{c}0.102 * * \\
(0.041)\end{array}$ & $\begin{array}{c}0.064^{* *} \\
(0.029)\end{array}$ & $\begin{array}{c}0.074 \\
(0.055)\end{array}$ \\
\hline$L G D P$ & $\begin{array}{l}-0.047 \\
(0.053)\end{array}$ & $\begin{array}{c}-0.125^{* * *} \\
(0.046)\end{array}$ & $\begin{array}{l}-0.054 \\
(0.052)\end{array}$ \\
\hline$L C P I$ & $\begin{array}{c}0.561 * * \\
(0.263)\end{array}$ & $\begin{array}{c}0.262 * * \\
(0.121)\end{array}$ & $\begin{array}{c}-0.317 * * * \\
(0.066)\end{array}$ \\
\hline LWAGES & $\begin{array}{c}0.034^{* *} \\
(0.014)\end{array}$ & $\begin{array}{c}0.023 * * \\
(0.014)\end{array}$ & $\begin{array}{l}-0.021 \\
(0.022)\end{array}$ \\
\hline LTRADE & - & - & $\begin{array}{c}-0.207 * * * \\
(0.029)\end{array}$ \\
\hline Constant & $\begin{array}{c}0.819 \\
(1.276)\end{array}$ & $\begin{array}{c}-2.286 * * * \\
(0.824)\end{array}$ & $\begin{array}{l}2.285^{*} \\
(1.255)\end{array}$ \\
\hline Observations & 219 & 219 & 210 \\
\hline $\begin{array}{l}\text { AR } 1 \text { [ } p \text {-value] } \\
\text { AR } 2 \text { [ } p \text {-value }\end{array}$ & $\begin{array}{l}0.067 \\
0.203\end{array}$ & $\begin{array}{l}0.077 \\
0.230\end{array}$ & $\begin{array}{l}0.073 \\
0.220\end{array}$ \\
\hline Hansen J [p-value] & 0.560 & 0.875 & 0.911 \\
\hline
\end{tabular}

Note: Standard errors in parentheses, $* * * p<0.01, * * p<0.05, * p<0.1$. The dependent variable in each regression is the log of unemployment and the number of countries that included in the regression is 47 developing countries. Significant time dummies are included in every regression.

When we use the physical index as a proxy, the IPRs maintains its positive sign and significance as in the baseline model. Other independent variables in all columns are similar in magnitudes if compared to the baseline model. The third robustness check shows that the coefficient of IPRs protection is still positive and significant and other variables are similar in signs and significance level. It is also important to highlight that the coefficients of the lag dependent variable in all columns are within the same range with the baseline model which is between $0.85-0.96$. The results show that the estimated baseline model not sensitive to changes in I explanatory variables and alternative proxies of IPRs. Thus, we can conclude that the estimated model is robust. 


\section{Conclusion}

Predicting unemployment in developing countries is a challenge as they may have lower efficiency of labor and may be struggling to maintain unemployment at the lowest rate compared to the developed countries. Thus, the implementation of IPRs protection is expected to affect unemployment in developing countries. The implementation of IPRs protection directly influences technology and innovation in the country. The main objective of this paper is to investigate a direct link between IPRs protection and unemployment in the selected developing countries. We use the data from 47 developing countries and the system GMM method for a sample period from 2008 to 2014. The motivation behind this study is the fact that the implementation of IPRs protection in developing countries will expectedly bring about certain consequences, generally on the macroeconomic issue and specifically on unemployment. As IPRs protection may affect technological innovation which is considered as an important element in the component of economic growth, understanding of the impact of IPRs protection on unemployment is crucial.

Based on the findings of the study, it can be concluded that IPRs protection increases unemployment in developing countries, as revealed by a positive and statistically significant coefficient between IPRs protection and unemployment. The positive relationship between IPRs protection implies that strengthening of IPRs protection accelerates unemployment in the selected developing countries in this study. The robustness checks also carried out in this study by substituting another two elements of the index in IPRI which are physical index and legal and political index as a proxy for IPRs. In addition, we conduct additional robustness tests by including, trade as an additional control variable. The coefficients of IPRs protection are still positive in all robustness checks, thus confirmed the results are robust.

In terms of policy implication, the policymakers should manage an appropriate level of IPRs protection in developing countries, in order to maintain a low level of unemployment. This is because the empirical finding provided a hint for policymakers to put any effort into monitoring an appropriate level of IPRs protection to maintain a desired unemployment level in the country. Further studies should consider the implication of IPRs protection on unemployment by considering each sector and dividing it with the sectors involved with IPRs protection. This is important to observe if there is a similar impact on the implementation of IPRs protection in the different sectors of the economy.

We also find that low levels of inflation, high economic growth, and education reduce unemployment. The future policy that involves inflation for example in monetary and fiscal policy, would benefit a country in terms of the reduction in unemployment in the selected developing countries Additionally, as economic growth also has a negative effect on unemployment, we would expect an increase in growth may reduce unemployment. This is because higher economic growth stimulates job opportunities. In addition, a special arrangement to focus on unemployment among graduate students should also be a priority. Since the researcher used tertiary education as a proxy for education, the positive coefficient can be interpreted as "the higher educational attainment, the longer the time people may need to accept a job". Meanwhile, people who have attained higher education level may consider searching for appropriate jobs and would rather be unemployed for that period. In the long run, people with lower educational attainment grab employment without considering whether the job is appropriate. 
INTERNATIONAL JOURNAL OF ACADEMIC RESEARCH ECONOMICS AND MANAGEMENT SCIENCES

Vol. 9, No. 2, 2020, E-ISSN: 2226-3624 @ 2020 HRMARS

\section{References}

Abegunde, D. O., Mathers, C. D., Adam, T., Ortegon, M., \& Strong, K. (2007). The burden and costs of chronic diseases in low-income and middle-income countries. Lancet, 370(9603), 1929-1938. http://doi.org/10.1016/S0140-6736(07)61696-1.

Arnold, L. G. (2002). On the growth effects of North-South trade: The role of labor market flexibility. Journal of International Economics, 58(2), 451-466. http://doi.org/10.1016/S0022-1996(01)00174-X.

Arellano, M., \& Bond, S. (1991). Some tests of specification for panel data: Monte Carlo evidence and an application to employment equations. The Review of Economic Studies, 58(2), 277. http://doi.org/10.2307/2297968.

Arellano, M., \& Bover, O. (1995). Another look at the instrumental variable estimation of errorcomponents models. Journal of econometrics, 68(1), 29-51.

Awad, A., \& Youssof, I. (2016). The impact of economic globalisation on unemployment: The Malaysian experience. The Journal of International Trade \& Economic Development, 8199(April), 1-21. http://doi.org/10.1080/09638199.2016.1151069

Balsmeier, B., \& Delanote, J. (2015). Employment growth heterogeneity under varying intellectual property rights regimes in European transition economies: Young vs. mature innovators. Journal of Comparative Economics, 43(4), 1069-1084. http://doi.org/10.1016/j.jce.2014.10.002

Bellak, C., Leibrecht, M., \& Riedl, A. (2008). Labour costs and FDI flows into Central and Eastern European Countries: A survey of the literature and empirical evidence. Structural Change and Economic Dynamics, 19(1), 17-37. http://doi.org/10.1016/j.strueco.2007.03.001

Blundell, R., \& Bond, S. (1998). Initial conditions and moment restrictions in dynamic panel data models. Journal of econometrics, 87(1), 115-143.

Falvey, R., \& Foster, N. (2006). The Role of Intellectual Property Rights in Technology Transfer and Economic Growth: Theory and Evidence, (April 2017), 100. http://doi.org/10.1111/j.1475-4932.1987.tb00650.x

Falvey, R., Foster, N., \& Greenaway, D. (2009). Trade, imitative ability and intellectual property rights. Review of World Economics, 145(3), 373-404. http://doi.org/10.1007/s10290009-0028-z

Fink, C. (2008). Enforcing Intellectual Property Rights: An Economic Perspectives. ICTSD (Ed), (July).

Furuoka, F. (2007). Does the "Phillips curve" really exist? New empirical evidence from Malaysia. Economics Bulletin, 5(16), 1-14.

Hannum, E., \& Buchmann, C. (2005). Global educational expansion and socio-economic development: An assessment of findings from the social sciences. World Development, 33(3), 333-354. http://doi.org/10.1016/j.worlddev.2004.10.001

Hasan, R., Mitra, D., Ranjan, P., \& Ahsan, R. N. (2012). Trade liberalization and unemployment: Theory and evidence from India. Journal of Development Economics, 97(2), 269-280. http://doi.org/10.1016/j.jdeveco.2011.04.002

Haydaroglu, C. (2015). The relationship between property rights and economic growth: An analysis of OECD and EU countries. Danube, 6(4), 217-239. http://doi.org/10.1515/danb2015-0014 
INTERNATIONAL JOURNAL OF ACADEMIC RESEARCH ECONOMICS AND MANAGEMENT SCIENCES

Levine, L. (2013). The increase in unemployment since 2007: Is it cyclical or structural? Congressional Research Service, 15(3), 1-17.

Mondal, D., \& Gupta, M. R. (2008). Intellectual property rights protection and unemployment in a North South model: A theoretical analysis. Economic Modelling, 25(3), 463-484. http://doi.org/10.1016/j.econmod.2007.07.006

Shin, S. H. (2017). The impact of intellectual property on provincial unemployment rates in South Korea.

Benjamin, V. Q. B. (2018). The relationships between inflation, wages and unemployment have not disappeared, (March), 19-34.

Wajid, A. (2013). The Impact of Inflation and Economic Growth on Unemployment. Proceedings of 3rd International Conference on Business Management (ISBN: 978-969-9368-07-3), 122.

\section{Appendix A}

List of countries included in the sample

Albania, Algeria, Armenia, Azerbaijan, Bangladesh, Benin, Botswana, Brazil, Bulgaria, Burundi, Cameroon, Chad, China, Costa Rica, Cote D'Ivoire, Egypt, Ethiopia, Georgia, Ghana, India, Indonesia, Jamaica, Jordan, Kazakhstan, Mecadonia, Madagascar, Malawi, Mali, Mautitania, Mauritius, Moldova, Morocco, Mozambique, Nepal, Pakistan, Philippines, Romania, Russian Fed., Rwanda, Senegal, Serbia, South Africa, Tanzania, Thailand, Tunisia, Uganda, Ukraine. 